\title{
Fine Needle Aspiration Cytology of Parapharyngeal Tumors
}

\author{
Kuldeep Singh* and Rahim Gousia \\ Dept. of Pathology, GMC Jammu. J \& K, India
}

ABSTRACT

Parapharyngeal space tumors (PPS) are rare, representing only $0.5 \%$ of head and neck neoplasm. 7 patients diagnosed with PPS tumors which presented to us within a span of two years were included. Cytopathologic evaluation was done by fine needle aspiration cytology, computed tomography and ultrasonography guidance wherever necessary. Histopathology confirmation was available in all the cases. The age of the patient ranged from 15-55 years with male to female ratio 1:1. The commonest clinical presentation was a slowly increasing painless mass in neck. Out of 7 cases the tumors encountered were pleomorphic adenoma (02), neurofibroma (01), Schwannoma (01), Paraganglioma (01), Lipoma (01), Angiofibroma (01). Two false negative cases were encountered. Overall diagnostic accuracy being $71.4 \%$.

With proper clinical and radiological assessment, FNAC can be extremely useful in diagnosing most of these lesions except a few which need histopathological confirmation.

Keywords: Parapharyngeal Space, Computed Tomography, Magnetic Resonance Imaging, Parapharyngeal Tumors, Cytology

\section{Introduction}

PPS is a rare location for head and neck tumors (1). It is a space in the supra hyoid neck that contain fat and is surrounded by several other spaces defined by the fascial layers of neck (15). Para pharyngeal space tumors often present therapeutic and preoperative diagnostic problems due to variable nonspecific symptoms and complex anatomy of the region. Most of the lesions (70-80\%) are benign (3) comprising of salivary gland tumors, neurogenic tumors and paragangliomas in descending order of frequency (17). Other rare tumors include lipoma, hemangioma, aneurysm, branchial cleft cyst, meningioma, chordoma, and sarcoma (2). On FNAC cytomorphology of meningioma mimics that of other head and neck tumours like acinic cell carcinoma and paraganglioma etc.(18). Therefore, the possibility of meningioma should be kept in the differential diagnosis of PPS tumour.

The most common malignant tumour in this region is adenoid cystic carcinoma by Spiro et al. (14). Malignant peripheral nerve sheath tumour is rare at this site and have grave prognosis (4). Occurrence of metastatic papillary thyroid carcinoma in the PPS is extremely rare (13).

The patient usually present with swelling of two specific sites namely oropharynx and lateral neck (cervical or submandibular mass), there may be oral cavity bulge, serious otitis, headache, syncope or even cranical nerve palsies involving vagus and hypoglossal nerves, leading to disorders of swallowing or speech(21).

The diagnosis is done by physical examination, radiological imaging, and pathological examination. Fine needle aspiration cytology (FNAC) can be an easy, rapid, and effective method of diagnosing these myriad of lesions of a specific anatomic space(9). Diagnostic difficulty persists due to their similar mode of presentations and at times morphological overlap. Hence, some cases can only be confirmed by histopath-ological examination. It is very important to diagnose the nature of tumor whether benign or malignant prior to therapy, because treatment protocol is variable and early diagnosis can give better survival rate.

\section{Material and Methods}

The present study was conducted on seven patients mainly presenting with painless mass in the neck. Other symptoms seen included foreign body sensation, dysphagia, hoarseness of voice and impaired hearing.Cytomorphological patterns were evaluated by doing FNAC with 10cc syringes and 22 gauge/24 gauge needle following the standard procedure (11). FNAC was also done under guidance (Computed tomography/ ultrasonography) as and when necessary. The smears were prepared in the usual manner. The wet smears were immediately fixed in isopropyl alcohol and latter stained by Papanicolaou and Hematoxylin\& Eosin. Air-dried smears were stained by May-GrunwaldGiemsa. Confirmation was done by histopathology (routine hematoxylin and eosin stain).

\section{Result}

Total seven cases of parapharyngeal space tumors were selected of which all were benign. The age ranged from 15-55 years with Male: Female ratio was 1:1. Maran et al. (8) and Pang et al.(12) also reported no sex predominance in their studies. The most common mode of presentation 
was gradually increasing painless mass in neck, the other symptoms being foreign body sensation, dysphagia, hoarseness of voice and impaired hearing (Table I). Radiological investigation revealed parapharyngeal space mass lesions in all the cases. All cases underwent surgery with histopathological examination to confirm the diagnosis. The most common surgical approach was transcervical (5cases), followed by transparotid and combined transcervicaltransparotid approach (1 case each)(Table II).

Out of 7 cases, 5 gave a satisfactory cytological material, in one case of paraganglioma only blood was aspirated, whereas case of angiofibroma cellularity was very scanty to diagnose. Histopathological confirmation of both the lesions was done after cytological detection.

Pleomorphic salivary adenoma (28.6\%) showed maximum incidence followed by neurofibroma (14.3\%), Schwannoma (14.3\%)(Fig.1), Paraganglioma (14.3\%), Lipoma (14.3\%), angiofibroma (14.3\%)( Table III).

Table I: Clinical Features of patients of PPS tumor.

\begin{tabular}{|l|c|}
\hline Clinical Features & No. of patients \\
\hline Painless mass in neck & 04 \\
\hline Dysphagia & 01 \\
\hline Hoarseness of voice & 01 \\
\hline Impaired Hearing & 01 \\
\hline Total & $\mathbf{0 7}$ \\
\hline
\end{tabular}

Table II: Surgical approaches in PPS Tumors

\begin{tabular}{|l|c|}
\hline Surgical Approach & Number of Cases \\
\hline Trans cervical & 05 \\
\hline Trans parotid & 01 \\
\hline Combined Trans cervical- arotid & 01 \\
\hline Total & $\mathbf{0 7}$ \\
\hline
\end{tabular}

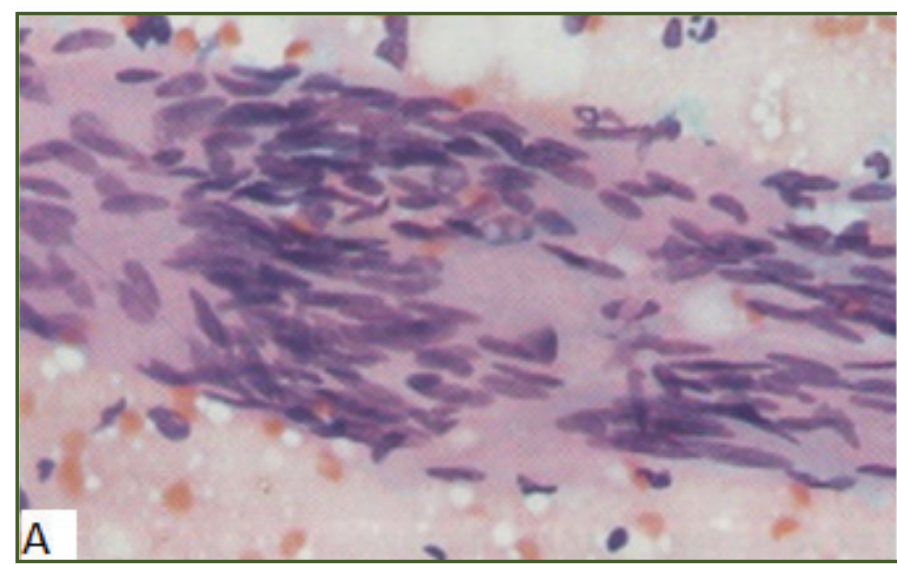

Fig. 1: Case Diagnosed as Schwannoma A. FNAC Show Spindle Cells
Table III: Diagnosis of Parapharyngeal space tumors

\begin{tabular}{|l|c|c|}
\hline Diagnosis & Number & Percentage \\
\hline Pleomorphic adenoma & 02 & $28.6 \%$ \\
\hline Neurofibroma & 01 & $14.3 \%$ \\
\hline Schwannoma & 01 & $14.3 \%$ \\
\hline Paraganglioma & 01 & $14.3 \%$ \\
\hline Lipoma & 01 & $14.3 \%$ \\
\hline Angiofibroma & 01 & $14.3 \%$ \\
\hline Total & $\mathbf{0 7}$ & \\
\hline
\end{tabular}

\section{Discussion}

Tumors of PPS have been of interest to head and neck surgeons because of wide variety of histologic tumors that occur in this space. Parapharyngeal tumors are difficult to diagnose early due to their location and plethora of presentation.

They are usually benign, pleomorphic adenoma arising from the deep lobe of parotid has been found to be the most common tumor of parapharyngeal region by several authors(1) and also by us. Studies have shown that there is no difference in the prognosis of pleomorphic adenoma even if they are cellular and show cytologicatypia in the form of scattered hyperchromaticnuclei(19).

Neurofibroma and Schwannomas are rather common tumors of parapharyngealspace(1). But their occurrence at this site, slow growth and associated neurological manifestations can mimic other entities(16). The paragangliomas occurring in head and neck comprise $3 \%$ of all parangangliomas and almost all located in PPS and arise in carotid body(5). Most follow a benign course, may be bilateral, multicentric or a component of multiple endocrine (MEN) syndrome. Histopathological confirmation was done to confirm the diagnosis.

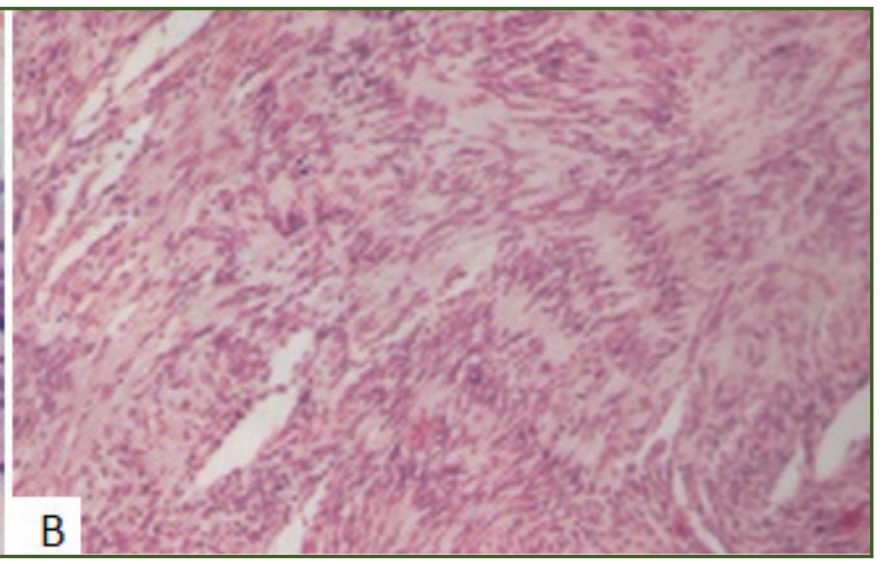

B. Histological Section with palisading (MGG x 400). 
Angiofibroma can also arise in the site(6), but we failed to diagnose them on cytology alone and most of these smears were grossly hemorrhagic with few spindle cells only.

Cytological diagnosis was almost corroborative with final histopathological diagnosis in all cases. True positive cases comprised 5(71.4\%), whereas there were only two false negative cases due to paucity of materials of difficulty in approaching the lesions. Thus, diagnostic accuracy in this series was approximately $71.4 \%$ which corroborated with the findings of earlier studies(10).

Parapharyngeal masses sometimes fail to be detected early due to their location and overalapping symptoms with other common illnesses. Their important lies in the fact that even benign lesions, if left untreated, may be fatal due to encroachment of vital structures. Clinical examination alone may not be sufficient to diagnose a mass or parapharyngeal lesion. High resolution CT scan has facilitated and contributed significantly to the preoperative assessment of these lesions. It helps in determining the size and extent of tumor origin, demonstrate the degree of tumor vascularity, differentiates benign from malignant lesions and its relation to major vessels(20). This assist in planning the management of tumor. MRI has also become a very useful diagnostic tool. With proper clinical and radiological assessment, FNAC can be extremely useful in diagnosing most of these lesions except a few which need histopathological confirmation.

\section{References}

1. Ahmed F, Waqar-Uddin, Khan MY, Khawar A, Bangush W, Aslam, J. Management of parapharyngeal space tumors. J Coll Physicians Surg Pak 2006; 7-10.

2. Chu W, Strawitz JG. Parapharyngeal growth of parotid tumor: Report of two cases. Arch Surg 1977; 709-11.

3. Fernandez Ferro M, Fernandez Sanroman J, Costas Lopez A, Sandoval Gutierrez J, Lopez de Sanchez A. Surgical treatment of benign parapharyngeal space tumors: Presentation of two clinical cases and revision of literature. Med Oral Pathol Oral Cir Bucal 2008: 61-4.

4. Graccion JG, Enzinger FM. Malignant schwannoma associated with von Recklinghausen neurofibromatosis. Virch- ows Arch (A) 1979: 43-57.

5. Lack E. Tumors of adrenal gland and extra adrenal paraganglioma: Atlas of tumor pathology 1997; Series 3, Washington DC: Fasc 19.
6. Laryngology and Head and Neck Surgery. In: Hibbert J, editor. Scott-Brown's otolaryngology. 6th ed. Oxford: Butter-worth-Heinemann; 2005.

7. Luna-Ortiz, Navarrte-Aleman JE, Grana-dos-Gracia M, Herrea-Gomez A. Primary parapharyngeal space tumors in Mexican cancer center. Otolaryngol Head Neck Surg 2005; 587-91.

8. Maran AG, Mackenzie IJ, Murray JA. The parapharyngeal space. J. Laryngol Otol. 1984 Apr; 98(4): 371-80.

9. Mondol A, Raychoudhury BK. Peroral fine needle aspiration cytology of parapharyngeal lesions. ActaCytol 1993; 694-8.

10. Mondol, A, Gupta S. The role of preoral fine needle aspiration cytology (FNAC) in the diagnosis of parapharyngeal lesions: A study of 51 cases: Indian J PatholMicrobiol 1993: 253-9.

11. Orell SR, Sterrett GF, Whitaker D. Techniques of FNA cytology. In: Orell SR, Sterrett GF, Whitaker D. editors. Fine needle aspiration cytology. 4thed. New York; Churchill Livingstone; 2005, P. 9-30.

12. Pang, KP, Goh CH, Tan HM. Parapharyngeal space tumors: an 18-year review. J Larngol Otol. 2002 Mar; 116 (3); 170-5.

13. Saydam L, Kalcioglu T, Demirkiran A, Gurer M. Occult Papillary thyroid carcinoma presenting as a parapharyngeal metastasis. Am J otolaryngol. 1999 May-June 20(3): 166-8.

14. Spiro RH, Huvos AG, Strong EW. Adenoid cystic carcinoma of salivary gland: A clinicopathologic study of 242 cases. Am J Surg 1974; 512-20.

15. Stambuk HE, Patel SG. Imaging of the parapharyngeal space.OtolayngolClin North Am 2008: 77-101.

16. Szmeja Z, Sefter W, Szymice E, Wierzbicka M, Zdanowicz E. Neurofi-broma of the parapharyngeal space: A case report. Otolaryngol Pol 1998: 215-7.

17. Tak B, Bhuie HS, Gupta, A.K. Paraphar-yngeal space tumors: An overview. Indian Journal of Otolaryngology and Head and neck surgery 2001, 53 (2) 173-75.

18. Tan LH. Meningioma presenting as a parapharyngeal tumor: report of a case with fine needle aspiration cytology. Actacytol.2001 Nov-Dec; 45(6) 1053-9.

19. Thunnissen FB, Peterse JL, Buchholtz R, Van der Beek JM, Bosman FT. Polyploidy in pleomorphic adenomas with cytologicatypia. Cytopathology 1992; 101-9.

20. Whyte AM, Hourihan MD. The diagnosis of tumours involving the parapharyngeal space by computed tomography.Br J Radiol. 1989 Jun; 62(738): 526-31.

21. Zhi KO, Ren WH, Zhang L, Wen YM, Zhang YC. Diagnosis and surgical approach of a parapharyngeal space neoplasms. Shanghai Kou Qiang Yi Zue 2007: 547-50.
*Corresponding author:
Dr. Kuldeep Singh, Associate professor; Dept. of Pathology, GMC Jammu. J \& K, India
Email: conifer1@indialines.com

Financial or other Competing Interests: None.
Date of Submission : 08.02.2017

Date of Acceptance : 03.03.2017

Date of Publication : 11.03.2017 